Considered as one of the most traditional expression of Rio de Janeiros's popular Carnival, the bate-bolas crews, known as "turmas", have a expressive variety of visual ex-pressions present not only in their costumes but also in their performances during the Carnival days. Despite the common sense, which consider this variety as a sign of deca-dence we'd like to stress its originality and richness, underlining the multiple meanings articulated by these groups and the struggle for the determination of a "right" way of dressing and performing.

Keywords: Bate-bola crews, Carnival, Rio de Janeiro 


\title{
Turmas de bate-bolas do carnaval contemporâneo do Rio de Janeiro: diversidade e dinâmica
}

\author{
Aline V. V. Gualda \\ PEREIRA
}

Luiz Felipe

FERREIRA

Os bate-bolas são considerados personagens tradicionais nos carnavais populares do Estado do Rio de Janeiro. Apresentando-se inicialmente como foliões isolados, eles passaram a se organizar em grupos, conhecidos como "turmas", que apresentam considerá-veis diferenças entre si. A variedade de trajes e comportamentos dessas turmas, entretan-to, costuma ser criticada como uma espécie de desvirtuamento de um formato "tradicional". Este artigo reúne alguns aspectos de uma experiência de pesquisa realizada com turmas de bate-bolas do Rio de Janeiro entre os anos 2006 e 2008. As observações e registros relatados, referentes ao estado da manifestação na ocasião, possibilitam que se compreenda as turmas de bate-bolas à luz das tensões e disputas de poder que incluem o próprio significado da brincadeira.

Palavras chave: Bate-bolas, Carnaval, Rio de Janeiro 
Reunindo de dois até mais de uma centena de integrantes, as atuais turmas de bate-bolas presentes do carnaval carioca são constituídas não somente de indivíduos que moram no mesmo bairro, torcem para um mesmo time de futebol ou integram a mesma turma de amigos, mas também por foliões que não têm qualquer vínculo além do pertencimento ao mesmo grupo de fantasiados. Seus membros são, predominantemente, indivíduos do sexo masculino, com idades entre 25 e 40 anos, a maioria residente em bairros das zonas Oeste e Norte da cidade do Rio de Janeiro.

Cada turma costuma ter pelo menos um líder. Conhecido como "cabeça de turma", é ele quem, normalmente, dá forma ao grupo e administra a brincadeira. Sua função consiste na escolha de um determinado tipo de fantasia e na definição de uma "performance" específica a ser executada pelo grupo, o que normalmente está associado com o tipo da fantasia.

Falamos em "tipos de fantasia" porque, embora a indumentária do bate-bola possa ser reconhecida por conter certos elementos materiais típicos (como o macacão, a máscara e a bexiga), atualmente não há um único padrão visual que corresponda à brincadeira. Existe, nos dias de hoje, um movimento constante de renovação na visualidade das fantasias, tornando as indumentárias cada vez mais complexas. Novos elementos materiais vêm sendo acrescidos, itens "tradicionais" são substituídos por outros mais "modernos" e novas técnicas de confecção de roupas são empregadas em busca de soluções inesperadas e, muitas vezes, inusitadas.

As fantasias das turmas de bate-bolas contemporâneas são produzidas por meio de uma espécie de combinação de elementos materiais pertencentes a um "referencial material" próprio da manifestação. A seguir descrevemos os principais destes elementos, acompanhados de ilustrações realizadas por Gualda, conforme a composição das fantasias de turmas de bate-bolas acompanhadas por nós entre 2006 e 2008.

1. Elementos da indumentária do bate-bola

1.1. Macacões

1.1.1. Macacão curto

Macacão de comprimento curto (aproxi-

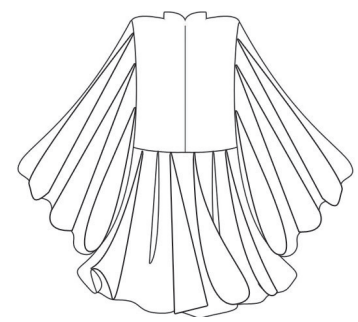

Figura 1 
Turmas de bate-bolas do carnaval contemporâneo do rio de janeiro: diversidade e dinâmica

madamente na altura dos joelhos), com mangas forradas. A parte de baixo do macacão corresponde a uma saia. Os tecidos empregados costumam ser os superfície lisa e brilhante, como o cetim, e podem ser usados nos padrões liso, listrado (com listras formadas pelo recorte e costura de tiras com cores diferentes alternadas), ou ainda estampados por meio de serigrafia.

\subsubsection{Macacão curto volumoso}

Macacão de comprimento variável entre curto a médio (podendo ficar um pouco abaixo da altura dos joelhos), com mangas bufantes

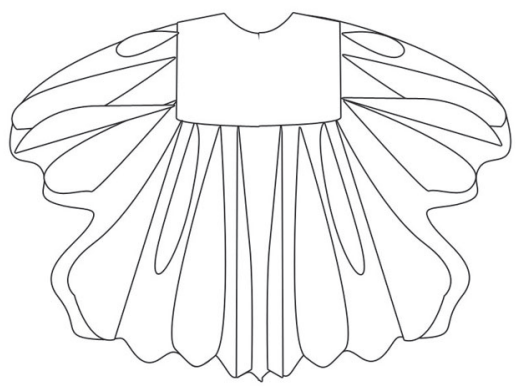

Figura 2 terminadas com elástico. A parte de baixo do macacão apresenta-se frequentemente em forma de saia, mas pode também corresponder à modelagem de calça comprida bufante. As mangas e saias (ou calças) deste macacão costumam ser bastante volumosas. Este efeito pode ser conseguido pela forragem do tecido com espuma fina ou através da costura das listras de tecido com linha de nylon. Os tecidos empregados são os mesmos do macacão curto.

\subsubsection{Macacão longo}

Macacão de comprimento longo, geralmente cobrindo os pés do fantasiado, com mangas compridas terminadas em elástico. A parte de baixo do macacão corresponde à forma de uma saia. Assim como no macacão curto volumoso, os tecidos podem formar um padrão listrado. Costuma-se utilizar uma grande metragem de tecido franzido neste tipo de macacão. Com isso, a fantasia geralmente se torna mais pesada do que as de outros modelos.

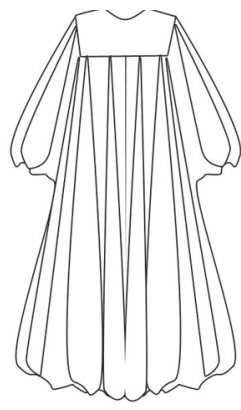

Figura 3 


\subsubsection{Macacão longo volumoso}

Macacão de comprimento médio a longo, sem mangas. Trata-se de uma peça bufante extremamente volumosa, que pende do pescoço cobrindo praticamente todo o corpo do fantasiado e que possui orifícios laterais para que se coloquem os braços. Seu desenho está representado na figura 4. Os tecidos empregados, geralmente cetim brilhante, são, quase sempre, unidos para formar um padrão listrado, como no macacão curto volumoso.

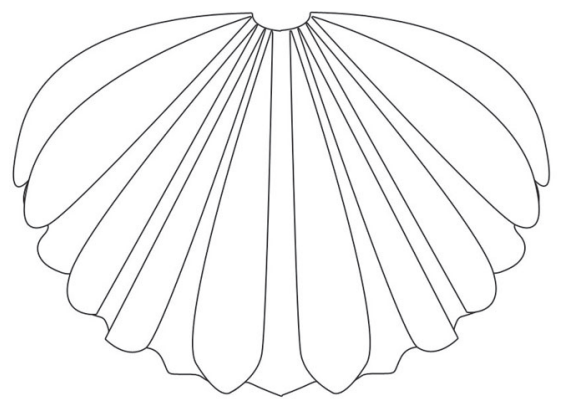

Figura 4

\subsection{Sobrevestes}

1.2.1. Casaca gliterada fechada

Casaca sem abertura, vestida sobre o macacão. Costuma ser confeccionada em tecido resistente, como o brim. Normalmente é forrada de espuma fina para se obter um aspecto "armado". Recebe

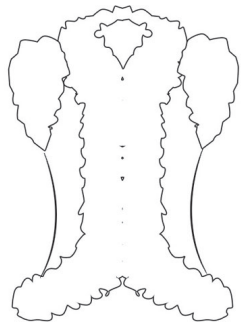

Figura 6 estampas feitas por meio de serigrafia e, sobre os motivos estampados ainda com tinta fresca, são

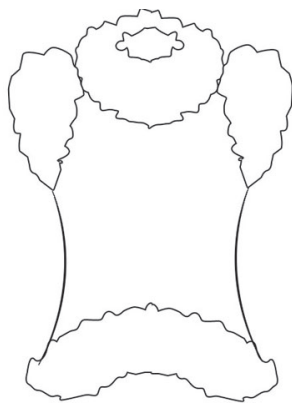

Figura 5 aplicadas camadas de gliter colorido. Costuma ser estampada com motivos temáticos. Os acabamentos na gola, nas cavas e na parte inferior da peça são feitos por meio da costura de boás de plumas ou similares. 
Turmas de bate-bolas do carnaval contemporâneo do rio de janeiro: diversidade e dinâmica

\subsubsection{Casaca gliterada com} abertura frontal

Similar à casaca gliterada fechada, com abertura frontal. Vestida, também, sobre o macacão.

\subsubsection{Peitoral}

Vestido pela cabeça, apóia-se sobre os ombros do folião. É usado sobre o macacão. Costuma ser confeccionado

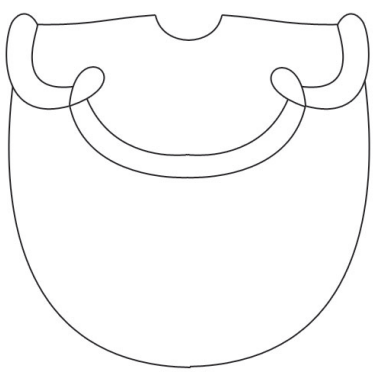

Figura 7 com técnicas variadas (aplique, bordado, ou mistas), predominantemente artesanais. Sua base pode ser feita de material emborrachado ou similar. Sobre a base aplicam-se mo-

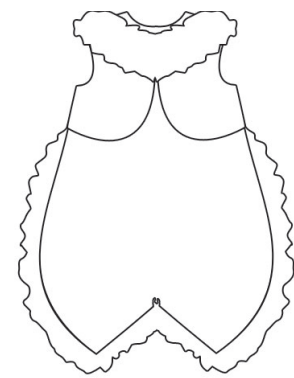

Figura 8 tivos temáticos por meio de trabalhos de modelagem, escultura, colagem, bordado, aplicação, instalação de pequenas luzes, entre outros.

\subsubsection{Bolero}

É vestido sobre o macacão. Possui parte frontal curta e parte traseira comprida. Normalmente é confeccionado em tecido com superfície lisa e brilhante, como o cetim. Costuma receber beneficiamento por meio de aplicações ou bordados feitos com paetês, miçangas e pequenos espelhos, formando desenhos. O acabamento de gola, cavas e extremidade inferior pode ser feito com boas, marabus, franjas ou materiais similares.

\subsubsection{Capa}

A capa, geralmente bordada, é usada amarrada no pescoço ou presa na fantasia. Pende sobre a parte traseira do macacão. Geralmente confeccionada com tecido de superfície lisa e brilhante, como o cetim. Costuma receber beneficiamento similares ao do bolero. O acabamento nas extremidades pode ser obtido com boás, marabus, franjas ou mate-

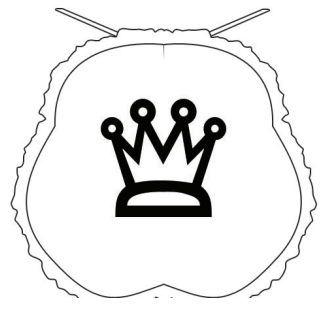

Figura 9 


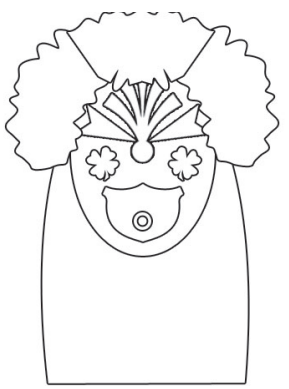

Figura 10

riais similares.

\subsection{Máscaras}

1.3.1. Máscara decorada

O "rosto" da máscara costuma ser feito de tela plástica e seus traços podem ser pintados por encomenda, de forma personalizada. A parte de tecido por trás da máscara, chamada de "capuz", costuma ser feita com lycra ou helanca e pode formar desenhos através do recorte e costura de partes com cores diferentes.

Este tipo de máscara costuma receber acabamento em formato de tiara feito por meio da colagem de boá de plumas ou similar.

\subsubsection{Máscara com peruca}

Possui "rosto" de acabamento similar ao da máscara decorada. O capuz é simples, normalmente feito em malha preta. Sobre a cabeça mascarada aplica-se uma peruca, confeccionada com técnicas e materiais diversos - como lã, cabelo sintéti$\mathrm{co}$, cilindros de tecido acolchoados com espuma ou acrylon que

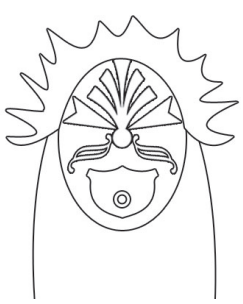

Figura 12

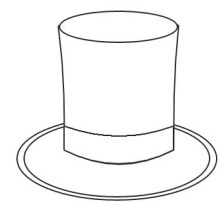

Figura 13

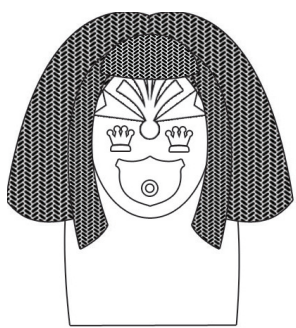

Figura 11 podem ou não ter estrutura interna de arame.

\subsubsection{Máscara simples}

Corresponde ao modelo industrializado. Não costuma receber beneficiamentos.

\subsection{Adereços}

1.4.1. Adereço de cabeça

Adereços de cabeça frequentemente são temáticos. Podem ser confeccionados com qualquer técnica e qualquer material. Não possuem formas específicas, podendo aparecer, por exemplo, como uma cartola, um peixe, um capacete de super-herói etc. 
Turmas de bate-bolas do carnaval contemporâneo do rio de janeiro: diversidade e dinâmica

\subsubsection{Bexiga}

É O artefato industrializado em formato oval, feito de material plástico inflado com ar. Possui orifício em uma das extremidades, por onde passa um cordão. O cordão da bexiga costuma ser atado a um bastão de madeira, pelo qual ela será manuseada. A bexiga pode ser

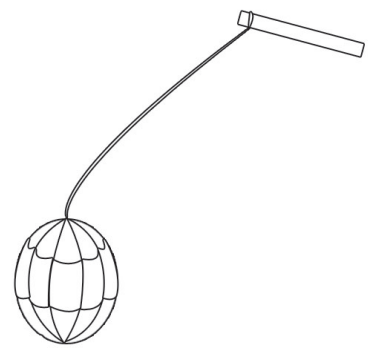

Figura 14 envolvida por uma espécie de trama feita com fios de nylon entrelaçados. Pode receber revestimento de camadas de cola e materiais ásperos, como a areia. A bexiga costuma ser girada no ar e batida no chão. O modelo industrializado substituiu as bexigas de animais (como porco ou boi), usadas anteriormente. A fantasia que emprega a bexiga pode também fazer uso de uma bandeira com o nome da turma ou elemento gráfico relacionado ao tema da fantasia.

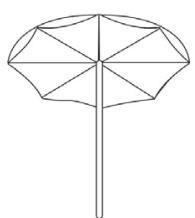

Figura 15
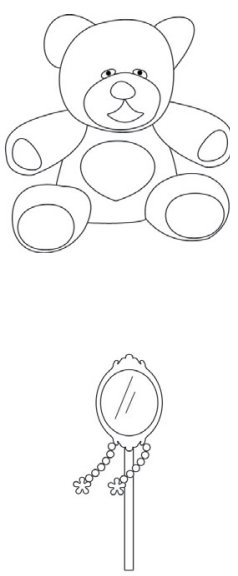

Figura 17

\subsubsection{Sombrinha}

É um adereço de mão bastante comum. Geralmente é decorada seguindo os mesmos motivos temáticos das fantasias, e costuma ser produzida com as mesmas técnicas com as quais as fantasias são confeccionadas. A sombrinha é frequentemente associada ao uso de um boneco de pelúcia, chamado simplesmente de "bicho" ou "boneco".

\subsubsection{Bicho (ou boneco)}

É um adereço de mão ligado ao tema da fantasia. Geralmente corresponde a um bicho de pelúcia industrializado, podendo também ser feito à mão por meio de modelagem em espuma.

\subsubsection{Adereço de mão temático}

De formato livre, costuma estar vinculado ao tema da fantasia. 


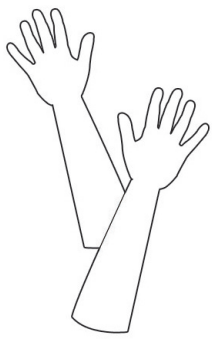

1.5. Cobertura de braços e pernas

1.5.1. Luvas

Geralmente compridas, as luvas costumam ser confeccionadas em lycra ou helanca com cores ou padrões relacionados ao tema da fantasia.

\subsubsection{Meiões}

Espécies de meia-calça usada sob o

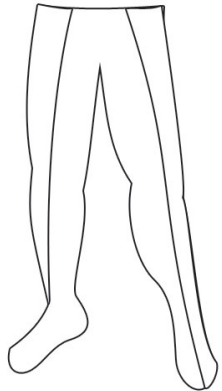

Figura 19

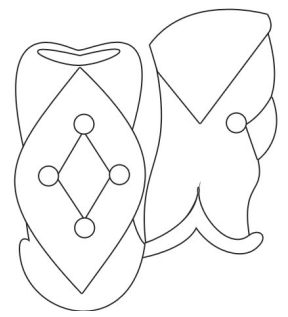

Figura 20 macacão. Normalmente são feitos de lycra ou helanca com cores ou padrões relacionados ao tema da fantasia. Podem receber recortes formando motivos gráficos.

\subsubsection{Botas}

São peças que complementam o calçado, mas não se confundem com eles. Apesar da denominação, são uma espécie de "polaina" de cano longo decorada com motivos gráficos. A base da bota costuma ser feita de material emborrachado. Seu fechamento, em volta da panturrilha, geralmente é realizado através de velcro.

\subsection{Calçados}

1.6.1 Tênis de marca

Quase sempre de grifes esportivas, como Nike, Adidas, Mizuno e Reebok, os tênis de marca podem ser usados com certas fantasias de bate-bolas. Constituem um dos componentes mais caros da fantasia.

\subsubsection{Sapatilhas personalizadas}

Normalmente são feitas sob encomenda. Costumam ser confeccionadas com lona ou material similar. Recebem recortes coloridos de tecidos brilhantes, combinando com a fantasia.

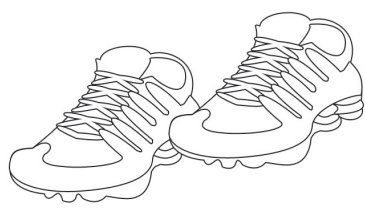

Figura 21 
Turmas de bate-bolas do carnaval contemporâneo do rio de janeiro: diversidade e dinâmica
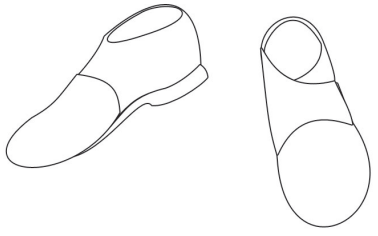

Figura 22

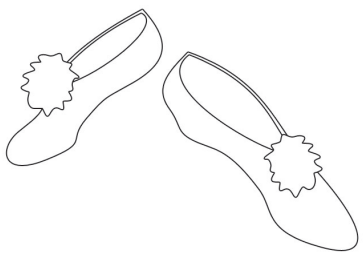

Figura 23

\subsubsection{Sapatilhas simples}

São compradas prontas em lojas de artigos carnavalescos. Costumam ser feitas de courino ou similares e sua abertura é costurada com elástico para ficar firme nos pés.

2. Combinação dos elementos da indumentária dos bate-bolas (os estilos)

Os elementos que compõem as indumentárias das turmas de bate-bolas contemporâneas não são combinados de maneira aleatória. Ao idealizar a fantasia do seu grupo, o cabeça da turma (ou outro membro que seja designado para a tarefa) considera, primeiramente, o estilo de roupa que corresponde a seu grupo. Os estilos "organizam" as relações de semelhança visual e de performance entre as turmas e também servem de parâmetro para a constituição da brincadeira de cada grupo. Categorias de classificação criadas pelos próprios foliões, estes estilos correspondem, cada um deles, a um "modelo" de fantasia que combina determinados elementos materiais.

É necessário observar, inicialmente, que os estilos e seus respectivos modelos de fantasia não se comportam como categorias fechadas e estáveis de classificação. Seu conjunto revela-se dinâmico, pois é constantemente atualizado, já que, com o uso, os elementos materiais e simbólicos que caracterizam um estilo podem ser substituídos por outros. Também ocorre de um estilo conservar a mesma configuração, mas mudar de denominação, ou de novos estilos surgirem, conforme apareçam novos elementos ou novas formas de articulação de elementos (desde que estas novidades sejam assimiladas de maneira consensual pelos brincantes).

Ainda que os estilos disseminem certos padrões visuais, há uma relativa liberdade de criação por parte dos idealizadores e produtores das fantasias das turmas. Desta forma as novidades vão sendo inseridas e, conforme aceitação coletiva, vão sendo incorporadas como novos referenciais.

Em nossas pesquisas, registramos, os seguintes estilos de bate-bola, com seus respectivos padrões de fantasias: 
Estilo "bola e bandeira" (ver Figura 24): tem esse nome devido ao uso conjunto da bexiga e da bandeira de mão. Sua fantasia característica costuma combinar os seguintes elementos: macacão curto estampado, liso ou listrado; casaca gliterada (normalmente fechada); máscara de tela decorada; bexiga e bandeira como adereços de mão; luvas, meiões e tênis de marca. Alguns macacões de fantasias do estilo apresentaram mangas com elástico nos punhos no lugar das mangas duplas (que são mais frequentes); também notou-se variação no uso da casaca fechada, que algumas turmas substituíram pelo modelo com abertura frontal. As máscaras também variaram. Foi registrado o uso de máscaras feitas de látex e tecido, em turmas de "bola e bandeira".

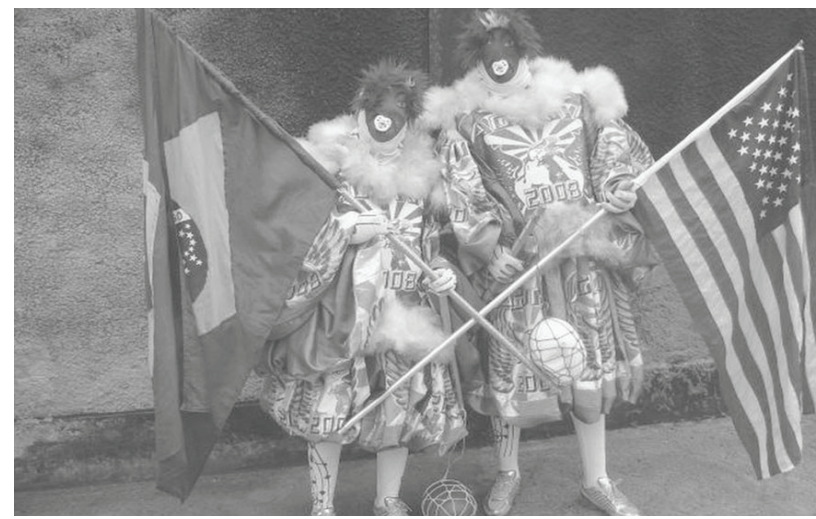

Figura 24 - Fantasia do estilo Bola e Bandeira (acervo dos autores).

Estilo "bicho e sombrinha" (ver Figura 25): também chamado de "bicho e boneco", apresenta dois adereços de mão característicos: a sombrinha e o bicho (ou boneco). A fantasia do bate-bola no estilo "bicho e sombrinha" costuma ser composta por macacão curto liso ou estampado; casaca gliterada (normalmente o modelo aberto na frente); máscara de tela decorada; sombrinha e bicho, como adereços de mão; luvas, meiões e capuz das máscaras feitos sob encomenda, com detalhes personalizados; sapatilhas de lona e tecido personalizadas.

Estilo "emília" (ver Figura 26): recebe este nome devido ao uso das perucas características. Há quem reconheça o estilo emília como próprio do bairro de Realengo, dada sua difusão na região. Por isso 
Turmas de bate-bolas do carnaval contemporâneo do rio de janeiro: diversidade e dinâmica

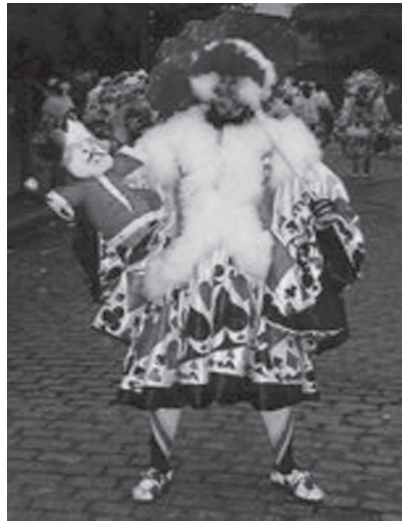

Figura 25 - fantasia do estilo Bicho e Sombrinha (acervo dos

este estilo também pode ser chamado de "estilo Realengo" ou "bate-bola Realengo". O estilo "emília" é marcado pelo uso de macacão amplo de comprimento médio cuja parte inferior pode ter formato de calça (neste caso se chama "macacão de perna") ou de saia. É constituído de listras regulares ou irregulares que podem receber estampas, casaca ou peitoral, luvas e meias, máscaras de materiais e tamanhos livres e variados, botas e bexigas além de outros acessórios de mão temáticos.

Estilo "rastafári" (ver Figura 27): Acredita-se que o nome deste estilo tenha relação com uma das fantasias usadas pela Turma do Vovô, do bairro de Santa Cruz, no Rio de Janeiro, que teria homenageado Bob Marley com roupas de bate-bolas complementadas por boinas rastafáris feitas em crochê, nas cores da bandeira jamaicana. A partir de então, as turmas

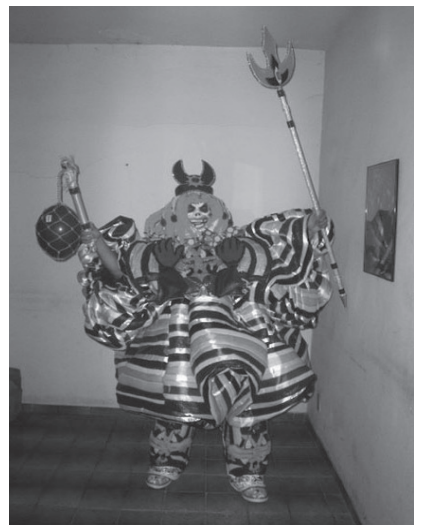

Figura 26- Fantasia do estilo Emília (acervo dos autores). com fantasias de configuração similar teriam sido associadas ao estilo, mesmo nos casos das que passaram a adotar outros complementos. $\mathrm{O}$ estilo é marcado pelo uso de macacão comprido e pesado com listras regulares; casaca ou bolero bordado, com a parte frontal mais curta e a parte traseira mais longa; máscara de tela; bexiga; acessório de mão e a possibilidade de se usar acessório de cabeça; luvas, meias e sapatilhas industrializadas.

Estilo "bujão" (ver Figura 28): O nome do estilo, bujão, ou peito de rolinha, refere-se ao tipo do macacão característico, que é o mais volumoso entre todos os tipos observados. Além do macacão similar a um grande rufo (ou "gola de palhaço"), que pende do pescoço cobrindo o corpo do fantasiado até as panturrilhas, usa-se uma longa e larga capa bordada. Este estilo de fantasia também emprega a máscara de tela (ou de outros materiais), meias, luvas, sapatilhas, bexiga e acessórios de cabeça e de mão temáticos. 


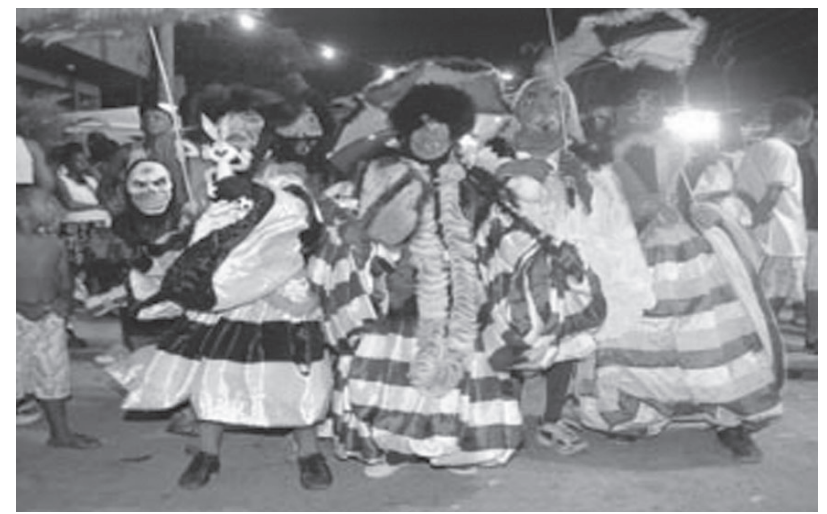

Figura 27 - Fantasia do estilo Rastafári (acervo dos autores).

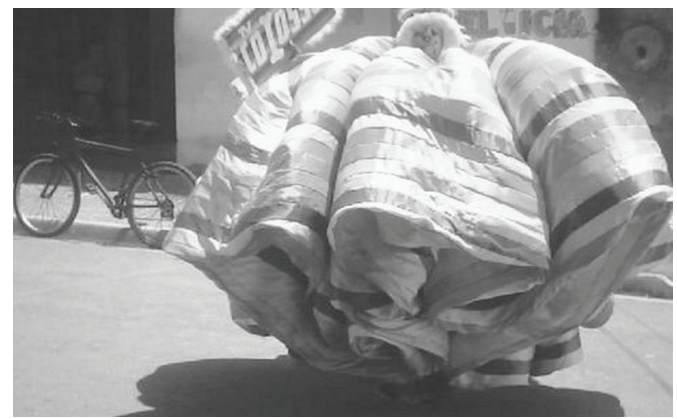

Figura 28 - Fantasia do estilo Bujão (acervo dos autores).

\section{Os temas}

Um dos principais espaços de criação das turmas e bate-bolas é a escolha dos temas das fantasias. Mudando a cada ano, tais temas norteiam a decoração das roupas influenciando as estampas nos macacões, os motivos gráficos das máscaras, casacas, peitorais, boleros e capas, a escolha dos adereços em geral e mesmo os materiais usados para confeccionar estas peças.

Quase sempre ligados à cultura de massa, os assuntos eleitos para temas de fantasias de bate-bola variam conforme o estilo adotado e o tipo de comportamento associado a cada grupo. Turmas de "bola e bandeira" costumam ser percebidas como as mais "agressivas"; turmas do estilo "emília" são vistas como as mais "artesanais", e assim por diante. Em outras palavras, dizemos que cada 
Turmas de bate-bolas do carnaval contemporâneo do rio de janeiro: diversidade e dinâmica

estilo carrega consigo uma espécie de perfil de comportamento reafirmado através dos temas escolhidos e da expressão visual das fantasias. Alguns exemplos surgidos dentre as turmas pesquisadas no período de 2006 a 2008:

"as turmas do estilo "bola e bandeira" costumam adotar como temas ícones da música popular, fatos históricos, super-heróis dos quadrinhos e ídolos do cinema (principalmente aqueles ligados a filmes de ação). Suas escolhas parecem privilegiar símbolos de força e agilidade.

-as turmas do estilo "bicho e sombrinha" preferem adotar temas relacionados aos desenhos animados, quadrinhos infantis e histórias de contos de fada. Suas escolhas frequentemente correspondem a temas mais lúdicos, singelos e coloridos.

-as turmas do estilo "emília" costumam possuir emblemas que simbolizam o grupo e, sendo assim, não mudam anualmente. Os desenhos dos emblemas normalmente são baseados em personagens de desenhos animados ou de histórias em quadrinhos. Eles compõem os elementos gráficos das fantasias, mas não aparecem sempre da mesma forma, pois são adaptados a temas que variam anualmente. Os temas escolhidos pelas turmas deste estilo costumam se basear em certos tipos mais ou menos fixos, como por exemplo "samurai", "mago", "Egito", "Zeus", "palhaço", entre outros. Pelo seu ecletismo visual e pela diversidade de técnicas empregadas na decoração temática das fantasias, as turmas deste estilo costumam ser vistas como as mais "modernas" e, ao mesmo tempo, as que empregam mais trabalho manual.

-As turmas do estilo "rastafári" pode ter emblemas e adotar temas, de maneira semelhante ao que fazem as turmas do estilo "emília". Entretanto, costumam seguir certas técnicas no beneficiamento de suas fantasias (como a do bordado) e não adotam as mudanças com muita facilidade. Por isso, são vistas como turmas tradicionais.

-As turmas do estilo "bujão" podem adotar temas. Com certa frequência aparecem logomarcas de produtos como refrigerantes, cigarros, grifes de moda e também escudos de times de futebol e artistas da mídia. Correspondem a um estilo definido recentemente e são percebidas como as turmas que usam elementos daquela que seria a fantasia "original" dos bate-bolas da Zona Oeste do Rio de 
Janeiro.

\section{A brincadeira}

Definidos os temas, parte-se para a aquisição dos materiais e, finalmente, chega-se à confecção. Por envolver tarefas relativamente complexas, o processo de criação e preparo das fantasias começa logo após o carnaval anterior. Estes passos costumam ser realizados em etapas que variam de acordo com o número de fantasias a serem confeccionadas e com a disponibilidade de recursos para a aquisição da matéria-prima necessária. O trabalho de confecção pode ser realizado pelos membros do grupo ou ser terceirizado, ficando, neste caso, a cargo de oficinas especializadas.

A brincadeira de bate-bola não consta simplesmente da produção e do ato de vestir uma fantasia específica durante o carnaval, mas baseia-se em certas formas de exibição, que denominaremos de performance.

As performances das turmas de bate-bolas podem ser analisadas em dois momentos distintos: (1) o período de constituição dos grupos e de preparo das fantasias, que pode se estender por meses antes do carnaval, quando os integrantes das turmas se reúnem em eventos variados e (2) o período carnavalesco, quando as turmas empreendem maneiras diferenciadas de aparição pública.

4.1. Performance fora do período carnavalesco

Antes do carnaval os integrantes de turmas de bate-bolas já se comportam como indivíduos que fazem parte de um mesmo grupo e que, desta forma, fazem uso compartilhado de elementos simbólicos de pertencimento, como o nome, o emblema, os hinos e os lemas da turma. Esses usos compartilhados se manifestam em determinadas circunstâncias (que na maioria das vezes são eventos para a arrecadação de recursos para o custeio da brincadeira carnavalesca) através das roupas que os membros do grupo vestem (as camisetas de turma) e na decoração e ambientação das suas reuniões (quando são usados bandeirões e são tocados os hinos da turma).

O nome da turma de bate-bolas parece ser o elemento mais comum e menos instável de referência à identidade. Não há regras para a formulação de nomes de turmas, porém percebe-se que muitos deles aludem a elementos da cultura de massa (Turma Zorra Total, Turma Animaniacs, Turma do Garfield, Turma do Eufrazino). Existem 
Turmas de bate-bolas do carnaval contemporâneo do rio de janeiro: diversidade e dinâmica

ainda nomes de turmas que se referem às suas localidades de origem (Turma da Praça, Turma da Amaral Costa, Turma da Vila Eugênia), e há os nomes mais genéricos, que encerram idéias às quais a turma quer ser associada (Turma da Amizade e Turma do Caos).

Um processo bastante semelhante ocorre na definição dos emblemas. Eles são símbolos visuais especialmente usados para representar os grupos. O desenho do emblema pode ser criado exclusivamente para este fim ou apropriado da cultura de massa. Neste caso, pode ocorrer de a turma produzir leituras próprias, espécies de novas versões de personagens de desenho animado, histórias em quadrinhos, contos de fada ou super-heróis. Alguns exemplos: o Calvin do emblema da Turma da Tropa, O Eufrazino Troca-Letras do emblema da Turma do Eufrazino, a Cuca do Sítio do Pica-Pau Amarelo, do emblema da Turma da Kuka, o Wolverine, da Turma Fascinação.

Além de definir seu nome e emblema, as turmas de bate-bolas podem promover a criação de músicas que as representem. Gravadas em estúdio, com recursos profissionais, ou produzidas de forma caseira estas músicas, chamadas de hinos, não possuem ritmos pré-definidos. Turmas mais organizadas produzem CDs com uma variedade de hinos criados para embalar um mesmo carnaval. Para compor seus hinos, as turmas costumam usar bases sonoras que variam entre o samba, o rap e o funk, referências musicais cotidianas no seu universo social.

Muitas turmas de bate-bolas também elaboram "enunciações" para exprimir como desejam ser identificadas. Estas enunciações são denominadas lemas e podem variar anualmente. Algumas turmas de bate-bolas combinam lema e emblema num elemento que se assemeIha às grandes bandeiras das torcidas organizadas de futebol, e que entre as turmas, são chamados de bandeirões. Trata-se de um tipo de estandarte de grandes dimensões geralmente exibido nas festas e eventos realizados antes ou durante o período do carnaval. Ele normalmente é amarrado em carros de som ou esticado sobre muros. As turmas que fazem bandeirões costumam apresentá-los em sua primeira aparição pública no carnaval.

A camiseta de turma é uma espécie de "uniforme". Diferentemente da fantasia, que é usada exclusivamente no período carnavalesco, a camiseta pode ser usada em qualquer eventualidade. Numa camiseta de turma podem vir impressos o nome, o emblema e o lema 
do grupo.

Além dos citados, há outros elementos, menos usuais, que também podem simbolizar a identidade coletiva das turmas, como, por exemplo, carteirinhas de identificação e adesão às comunidades virtuais no Orkut, rede social da Internet muito utilizada pelas turmas e bate-bolas.

\subsection{Performance durante o período carnavalesco}

Quanto às performances realizadas no período carnavalesco, também se nota uma grande variedade. A primeira aparição pública das turmas de bate-bolas no carnaval costuma constituir um evento ritual conhecido como "saída de turma" e pode requerer diferentes níveis de preparação antecipada, mostrando variados graus complexidade. Geralmente as saídas ocorrem nos domingos de carnaval, mas esta não é uma regra rígida, pois também há turmas que realizam suas saídas nos sábados de carnaval.

Para algumas turmas, o momento da saída constitui o auge da brincadeira. As informações do local, do dia e do horário do evento são transmitidas informalmente para a comunidade, geralmente por comunicação oral, momentos antes de acontecer.

As saídas de turma podem ser aguardadas com ansiedade pelo público espectador. De acordo com o volume de espectadores que costuma ter relação com o poder e a fama das turmas - pode haver, inclusive, uma estrutura rudimentar de comerciantes ambulantes no local. Para anunciar que é chegada a hora de abrir os portões e liberar a passagem dos fantasiados, algumas turmas promovem queima de fogos. É comum também haver sonorização do evento, através de equipamentos de som montados no local ou do uso de carros de som. No momento da saída, o hino da turma costuma ser tocado e então, os fantasiados tomam o espaço público apresentando uma espécie de coreografia constituída por muita correria, movimento e barulho. Em seguida, os fantasiados costumam posar (com ou sem máscaras) para fotos e filmagens. Toda esta apresentação dura entre 15 e 20 minutos, em média. Passado este tempo, os bate-bolas tendem a se dispersar em grupos menores pelas redondezas, voltando a se reunir mais tarde para circularem juntos nos carnavais de coreto de outras localidades da cidade ou para participarem de concursos de fantasias.

Há turmas que não priorizam o momento da saída. Para elas, 
Turmas de bate-bolas do carnaval contemporâneo do rio de janeiro: diversidade e dinâmica

a circulação pelas ruas, ou "passeio", costuma ser a forma mais expressiva da brincadeira. Os passeios curtos, realizados a pé, são mais valorizados entre as turmas que usam fantasias mais volumosas e pesadas. Existem turmas que preferem deslocar-se para localidades mais afastadas em vez de circularem somente pelas ruas do próprio bairro. Nestes casos, utiliza-se transporte fretado (ônibus, kombis ou vans) ou o trem para os deslocamentos. Normalmente os roteiros de passeio seguidos pelas turmas durante o carnaval são definidos com antecedência e as paradas escolhidas costumam privilegiar pontos estratégicos do carnaval, evitando-se, na maioria dos casos, passar pelos lugares freqüentados por turmas rivais.

Além das saídas e passeios há os concursos de fantasias, que são eventos de relativa importância no universo dos bate-bolas. Atualmente são realizados concursos de fantasias de bate-bolas em alguns bairros da cidade além do Concurso Folião Original, disputa oficial promovida pela Riotur, que ocorre na terça-feira de carnaval, na Cinelândia, no centro da cidade do Rio de Janeiro, espécie de espaço "neutro" para as turmas.

Existem ainda formas não-oficializadas de disputa entre as turmas de bate-bolas. Nestes "concursos" não-oficiais, os critérios são livres: compete-se pelo posto de turma mais numerosa, com fantasia mais bonita, com o tênis mais caro, com o maior ou o mais expressivo uso de inovações, de turma mais tradicional e de grupo mais popular entre outros "quesitos". Estas disputas também costumam ser resolvidas informalmente, seja pela síntese dos comentários correntes acerca do desempenho ou do sucesso de cada uma delas, seja pelo embate corporal entre os componentes de turmas rivais.

Entre as variações de performance e os diferentes estilos de bate-bolas também se percebem certas associações, como se vê a seguir:

-Turmas do estilo "bola e bandeira" e "bicho e sombrinha": costumam realizar saída, passeios locais e de roteiro e participam de concursos de fantasia.

-Turmas do estilo "emília": costumam realizar saída, passeio local (com mais freqüência do que o de roteiro, pois, conforme afirmam os fantasiados, o volume e o peso das fantasias dificultaria o deslocamento, mesmo usando transporte entre bairros) e geralmente participam de concursos de fantasia locais. É raro ver-se turmas deste estilo no Concurso Folião Original da Cinelândia, na terça-feira de 
carnaval.

-Turmas do estilo "rastafári": não costumam fazer da hora da saída um momento muito importante e os seus passeios normalmente se restringem às ruas de seu bairro de origem e arredores. Vale notar que as turmas do estilo rastafári não são muito numerosas. Para elas, parece ser importante ocupar o espaço público com fantasias grandiosas, pesadas, que denotem capacidade física como uma espécie de atributo masculino e, por extensão, como um indicador de poder

-Turmas do estilo "bujão": sua performance se restringe às aparições locais, pois, de acordo com os fantasiados, a roupa limitaria maiores movimentos e andanças de longa distância.

\section{Conclusão}

Notamos que os estudos anteriores sobre os bate-bolas tendem a se concentrar nos aspectos mais regulares da brincadeira. Produzidos, em sua maioria, entre as décadas de 1970 e 1980, eles costumam priorizar o aspecto folclórico da manifestação. Por causa deste enfoque, suas teorizações e descrições acabaram por deixar em plano secundário as variedades da brincadeira, seus hibridismos de elementos e as dinâmicas das significações associadas a eles. Sob esta perspectiva, as manifestações de composição híbrida e suas ditas impurezas, especialmente as resultantes dos processos de interação com os elementos massivos da cultura, tendem a ser vistas negativamente e costumam, até mesmo, ser desconsideradas enquanto objetos culturais válidos e passíveis de atenção acadêmica.

Analisando a maneira como a diversidade deve ser abordada pelos estudiosos, Clifford Geertz (1989) defende que somente uma compreensão contextualizada de cada manifestação pode ser eficaz para se evitarem abordagens etnocentristas ou reducionistas.

Neste sentido, as turmas dos bate-bolas devem ser tratadas não como "um idioma a ser interpretado" (GEERTZ, 1989, p. 181), já que os valores e significados de seus textos e práticas são instáveis, dinâmicos e produto de diferentes olhares (STOREY, 2005), mas a partir das múltiplas formas sob as quais as próprias turmas se articulam, destacando-se não suas similaridades, mas as disjunções, rupturas e conflitos característicos de suas tensões

Baseamo-nos num conceito de cultura definido não como a expressão orgânica de uma comunidade, mas como um conjunto con- 
Turmas de bate-bolas do carnaval contemporâneo do rio de janeiro: diversidade e dinâmica

testado e conflituoso de práticas de representação atrelados aos processos de formação dos grupos sociais (FROW e MORRIS, 1996), que não deve ser compreendido unicamente a partir de suas permanências, mas, principalmente, a partir de suas constantes modificações.

Esta é uma abordagem que convida a se compreender a cultura popular como o campo das impurezas, da mistura de conceitos, das apropriações de elementos cotidianos e das leituras particularizadas dos elementos massivos da cultura.

A manifestação das turmas de bate-bolas não possui, desse modo, um modelo paradigmático fixo, ou seja, ela não é praticada de maneira padronizada entre os diversos grupos de brincantes, mas estabelece-se como uma articulação de discursos diferenciados e, às vezes, até mesmo conflitantes. Neste sentido, o conceito de texto usado pelos Estudos Culturais pode ser útil. Um texto, se define como um elemento (objeto ou prática cultural) sobre o qual diferentes significados são atribuídos, provenientes de diferentes olhares que, por sua vez refletem uma multiplicidade de interesses (FROW e MORRIS, 1996; STOREY, 2005). Estes olhares/leituras, por sua vez, não estabelecem entre si qualquer tipo de hierarquia, não existindo, desse modo, uma forma "correta" de se compreender um texto e nem, no caso dos bate-bolas, de se participar de uma dada manifestação cultural (FISKE, 1989), pois a sua leitura estará sempre relacionada ao ponto de vista do observador.

A leitura de um texto resulta, então, da combinação de uma compreensão global do objeto cultural lido com o repertório particular das chaves de compreensão das quais cada leitor dispõe para assimilá-lo. Entretanto, por mais distanciados que possam ser os pontos de vista de leitores diferentes, eles sempre estarão relacionados em um mesmo ponto nodal: o do texto, que lhes é igualmente oferecido à leitura. Por isso, as ações e objetos que se articulam para definirem uma determinada brincadeira de bate-bola constituem um inventário dinâmico, bastante amplo, mas que é limitado por uma espécie de acordo simbólico constantemente revisto, entre todos os envolvidos na brincadeira. É por isso que as ações e os elementos que compõem brincadeiras de bate-bolas são heterogêneos, mas, ao mesmo tempo, mantêm um contato muito estreito uns com os outros.

A predominância da característica do dissenso na manifestação 
das turmas de bate-bolas, em algumas situações, é bastante explícita, e pode ser diferenciada em duas situações:

(1) As turmas de bate-bolas elaboram leituras próprias do personagem bate-bola, que são próprias a seus usos/leituras e que não são nem necessária, nem intencionalmente distintas das leituras dos demais grupos.

(2) Pode haver uma intencionalidade em ser diferente dos outros brincantes, justificada pelo desejo do pioneirismo de certos usos. "Determinar" a origem de um dos elementos incorporados à prática cultural como característico da manifestação resultaria numa posição de poder.

A disputa pelos significados dos objetos culturais também pode ser compreendida através do conceito de hegemonia. A formulação do conceito original, em Gramsci, refere-se a uma condição em processo, em que uma classe dominante não somente governa uma sociedade, mas a lidera através do exercício de autoridade moral e intelectual. A despeito da noção implícita de disputa, este conceito é usado para sugerir uma sociedade na qual existe um alto nível de consenso e onde o conflito mantém-se contido, conduzido para portos ideologicamente seguros. (STOREY, 2005)

Neste sentido, as manifestações culturais populares deixam de ser vistas como espaços de simples aceitação passiva de imposições de uma cultura dominante e passaram a ser entendidas como arenas de disputas hegemônicas de significados. (PORTELLI, 1977; GRAMSCI, 1998; BENNET, 1998; HALL, 1997, 2003, 2005)

Embora tenhamos identificado alguns dos elementos gerais da manifestação dos bate-bolas nos dias atuais e embora os tenhamos associado a alguns usos correntes, ressaltamos que não é possível esgotar as possibilidades de descrição e de análise dos elementos característicos da brincadeira, em sua totalidade, pois eles estão em constante redefinição e os seus significados são sempre instáveis, por serem disputados.

A manifestação contemporânea dos bate-bolas pode, então, ser vista como um objeto cultural complexo, tenso, disputado, numa espécie de luta onde se lida com adesões e recusas simbólicas. Nesta manifestação, os brincantes ora se submetem às regras alheias, ora determinam regras para o jogo. São agentes culturais em potencial, e sua ação se manifesta por meio do consumo particularizado, ou 
Turmas de bate-bolas do carnaval contemporâneo do rio de janeiro: diversidade e dinâmica

seja, pelas formas próprias de uso dos bens simbólicos estabelecidos no seio do universo conceitual da manifestação.

\section{Referências}

BENNETT, T. Popular culture and the "turn to Gramsci". In: STOREY, J. (org.). Cultural theory and popular culture: a reader. Essex: Pearson Education Limited, 1998, p. 217-224.

FISKE, J. Understanding popular culture. London and New York: Routledge, 1989.

FROW, J. e MORRIS, M. Australian cultural studies. In: STOREY, J. (org.). What is cultural studies? A reader. London: Arnold, 1996, p.344-367.

GEERTZ, Clifford. O saber local: novos ensaios em antropologia interpretativa. Petrópolis: Vozes, 1989.

GRAMSCI, A. Hegemony, intellectuals and the state. In: STOREY, J. (org.). Cultural theory and popular culture: a reader. Essex: Pearson Education Limited, 1998, p. 210-216.

HALL, S. Representation: cultural representations and signifying practices. London: Sage Publications, 1997.

Da dispora: identidades e mediaes culturais. Belo Horizonte: Editora UFMG, 2003.

A identidade cultural na ps-modernidade. Rio de Janeiro:

DP\&A, 2005.

PORTELLI. H. Gramsci e o bloco histrico. Rio de Janeiro: Paz e Terra, 1977.

STOREY, J. Culture theory and popular culture: an introduction. Essex: Pearson Educational Limited, 2005. 
Turmas de bate-bolas do carnaval contemporâneo do rio de janeiro: diversidade e dinâmica

\footnotetext{
Aline V. V. Gualda Pereira

Mestre em Artes (PPGARTES/UERJ) com a dissertação "Tramas simbólicas: a dinâmica das turmas de bate-bolas do Rio de Janeiro". Especialista em Estudos da Moda e Indumentária. Possui artigos publicados no livro Carnaval em Múltiplos Planos (Editora Aeroplano) e na revista Concinnitas (UERJ/ DEART).

E-mail: alinegualda@hotmail.com
}

\section{Luiz Felipe Ferreira}

Professor adjunto do Instituto de Artes e Coordenador da Pós-Graduação em Artes da Uerj. Coordenador do Centro de Referência do Carnaval. Autor dos livros Inventado Carnavais (Editora UFRJ), O Livro de Ouro do Carnaval Brasileiro (Ediouro) e Meu Carnaval Brasil (Editora Aprazível).

E-mail: felipeferreira@pobox.com 